\title{
Searching for Comparative Value in Small and Medium-Sized Alternative Accommodation: A Synthesis Approach ${ }^{1}$
}

\author{
Unji Baek², Seul-Ki Lee ${ }^{3}$
}

Received: April 13, 2018. Revised: April 30, 2018. Accepted: May 5, 2018.

\begin{abstract}
In the contemporary era of smart tourism, travelers face more accommodation options than ever before. The rapid expansions of alternative accommodation sector are partially owing to the growth of electronic commerce and the rise of online intermediary platforms. Online travel agencies serve as a critical distribution channel for tourism sectors, and the significance is further increased for small and micro entrepreneurs whose direct communication channels are scarce. Considering the holistic process of customer experience started with a third-party online intermediary, this study explores basic and extended attributes of small and medium-sized alternative accommodation where the comparative value is created. In order to achieve the objective, a research design was developed to synthesize the qualitative evidence. The synthesis encompasses both theoretical and practical perspectives, from a systematic review and opinions of academic professionals to an in-depth interview with an industry expert and the current practices of online travel agencies. This study suggests that the sources of value creation for alternative accommodation are not always consistent with those of the traditional. Accounting for the temporal and spatial dynamics in customer experience, the findings of this study provide insights on the comparative value of alternative accommodation, to both academic and industry audiences.
\end{abstract}

Keywords: Alternative Accommodation, Small and Medium Enterprise (SME), On-line Travel Agency (OTA), Customer Evaluation, Expert Interview.

JEL Classification Code: D30, L83, M31, O33.

\section{Introduction}

In the contemporary era of smart tourism characterized by digitalization and ubiquity, travelers are facing more accommodation options than ever before( $\mathrm{Li}, \mathrm{Hu}$, Huang, \& Duan, 2017; Niner, 2004). The burst of such innovative types of alternatives is owing to the expansion of distribution channel, featured by the fourth industrial revolution and electronic commerce (e-commerce). Traditionally, hotels and motels were the dominant lodging choices for those looking for a temporary stay outside their usual residential boundaries. However, as the development of information communication technologies and the infrastructure led to a

1 This work was supported by the Ministry of Education in Korea and the National Research Foundation of Korea (NRF2016S1A5A8020493).

2 First Author, Tourism Industry Data Analytics Lab (TIDAL), Sejong University, Korea. E-mail: jiunwhite@gmail.com

3 Corresponding Author. TIDAL, Department of Hotel and Tourism Management, Sejong University, Korea.

E-mail: seulkilee@sejong.ac.kr reduction of searching cost for guests and marketing cost for small and medium-sized ventures, the accommodation sector has witnessed the sudden emergence of new lodging products. For example, the peer-to-peer(P2P) accommodation has witnessed rapid growth, even exceeding the revenue growth of some chain hotels (Belarmino, Whalen, Koh, \& Bowen, 2017; Guttentag \& Smith, 2017; Tussyadiah \& Zach, 2017). Guesthouses and B\&Bs are now considered a popular method to enhance the value of residential properties, and homeowners are increasingly adding annexes and auxiliary rooms to their homes as the expected cash flows from the new unit is expected to easily justify the investment(Blum, 2014). Nontraditional hostels are also moving outside their conventional areas of operation(Amblee, 2015). More importantly, these accommodation alternatives can cater to business travelers and specialize in community events by immersing travelers into the local, residential ambiance, which have not been considered a business segment for such accommodation until now(Brochado \& Rita, 2016; Gardiner \& Scott, 2014). Development of e-commerce and intermediary platforms represented by online travel agencies (OTAs) has enabled 
such diversity of accommodation alternatives competing on the same space(Gazzoli, Kim, \& Palakurthi, 2008; Inversini \& Masiero, 2014).

The current practice of the OTAs' platforms usually applies the generalized customer rating framework for all the properties when providing information about the accommodation regardless of the types. The situation is not very different for devoted agents of $\mathrm{P} 2 \mathrm{P}$ accommodation or other alternative accommodation transactions. However, it is argued that the experience of travelers staying in alternative accommodations is fundamentally different from the traditional options such as hotels and motels(e.g., Gunasekaran \& Anandkumar, 2012; Tussyadiah, 2016; Tussyadiah \& Zach, 2017). For instance, some want to enhance their stay experiences through interactions with residents and other travelers, whereas traditional accommodation does not facilitate such exchanges, or even when so, only to a limited degree(Smaliukiene, Chi-Shiun, \& Sizovaite, 2015). Although customer review on the platforms allows a certain extent of freedom for the evaluators as electronic word-of-mouth (e-WOM), the unique value may not be holistically captured with the existing instruments and ratings currently implemented in the industry.

OTAs serve as a critical distribution channel for tourism sectors, and they become more crucial for small and micro entrepreneurs whose direct communication channels with the customers are scarce. However, little study actively integrates alternative accommodation and the distribution channel, apart from specifying one type of accommodation or a source of customer review. Conspicuously, despite the rapid expansions of the alternative accommodation sector, the inquiries on the unique value and the felicitous attributes have comparatively lacked. On the symbiotic relationship between small and medium-sized alternative accommodation and online intermediaries, this study aims to explore the comparative value of alternative accommodation in the holistic process of customer experience from online to offline, and from pre-stay to poststay. In order to achieve the purpose, this study takes a synthesis approach. Specifically, industry practices investigated with in-depth interview and OTA rating framework, followed by systematic review and expert panel opinion so that extended insights are summated.

\section{Theoretical Background}

\subsection{Alternative Accommodation}

Alternative accommodation types have been paid gradual attention for more than 50 years, although the terms used have not necessarily been identical(Gunasekaran \&
Anandkumar, 2012; Lynch, 2005; Morrison, Morcardo, Nadkarni, \& O'Leary, 1996). For example, Schwaniger(1989) noted that a night spent in a traditional hotel had been substituted by new forms of accommodation, and 'parahotels' had gained importance during last 30 years, meaning the movement was extant even in the 60's. Morrison et al.(1996) classified these owner-operated small and medium accommodation enterprises as 'specialist accommodation'(Pearce \& Moscardo, 1992) which have (1) guest-host interaction, (2) benefit from the physical attributes, and (3) special activities offered. Lynch(2005) coined the term 'commercial home' when describing small owner-operated commercial accommodation, particularly smaller than specialist accommodation in size. Researchers have tried to define the non-traditional accommodation sector; however, a consensus has not yet been reached. More recently, Gunasekaran and Anandkumar(2012) used the term 'alternative accommodation' to refer to alternatives other than traditional lodging options represented by hotel and motel, citing commercial homes, bed and breakfasts, guesthouses, homestays and service apartments as examples.

Semantically, alternative lodging types are not limited to the features of the properties or activities associated. Hence, they are not necessarily operated by small and medium enterprises, or regulated by the lodging options aforementioned. However, there should be a criterion distinguishing them into traditional and alternative, and Web can be a consensual turning point igniting the neoteric distributional era. After a few decades of Global Distribution system (GDS) dominance in tourism distribution, the Internet and e-commerce have rapidly replaced the position in the 1990s, facilitating electronic distribution of tourism commodities including accommodation sectors(Law, Leung, Lo, Leung, \& Fong, 2015; Morosan \& Jeong, 2008; Thakran \& Verma, 2013). Although the technology and the opportunity were identically enjoyable for two different types of channels, property-owned and third-party, namely, the impacts were asymmetrical. Consumers tend to show a more favorable attitude toward third-party intermediaries compared to property-owned websites, partially due to asymmetric usability and ease of use that they perceive(Morosan \& Jeong, 2008). This has promoted the growth of online intermediaries providing information and booking/payment services for accommodation, where innovation and dissemination of various alternative accommodation types and enterprises have been triggered. On the foundation of relevant literature and the phase of the industrial revolution, this study defines alternative accommodation as a non-traditional version of the accommodation sector provided as an alternative to traditionally familiar lodging options for consumers by the 
benefit of e-commerce, not restricted to the property size or providing special activities.

\subsection{Small and Medium-sized Alternative Accommodation and Online Travel Intermediaries}

Disintermediation from traditional intermediaries has increased the share of another form of intermediaries, represented by online travel agencies (OTAs), networking suppliers and consumers directly(Buhalis \& Law, 2008; Law et al., 2015; Thakran \& Verma, 2013). As distribution of tourism commodity involves providing information and the functional services in the process of making reservation and payment(Bastakis, Buhalis, \& Butler, 2004; Sthapit, Jo, \& Hwang, 2016), OTAs are important distributional channels for alternative accommodation spanning from information generated by, not only suppliers, but also consumers to the booking/payment process. The OTAs play a role in web rooms especially for the accommodation sector. Webrooming refers to a consumer behavior seeking information online and buying offline(Kang, 2018; Verhoef, Kannan, \& Inman, 2015). In terms of accommodation commodities, consumers may seek information and pay online. However, accommodation service is experiential in nature and inevitably engages in the onsite property. The transaction process is only completed once the consumer comes to and stays at the property, and any fee associated without the actual stay is to urge the completion of the transaction. As a result, for the users searching for an accommodation via online channels including OTAs, both online and offline experience affect the overall evaluation of an accommodation, albeit different in the objects. Webrooming and the holistic accommodation experience are thus temporally and spatially dynamic, and encompassing pre- to post-stay stages of both suppliers and consumers. <Figure 1> illustrates the dynamics of the experience.

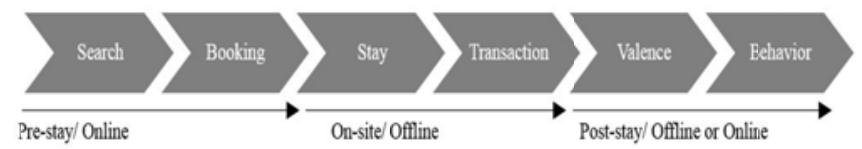

Figure 1. Temporal and spatial dynamics associated with the experience of accommodation distributed online

Unlike branded hotels that consumers are informed about and have brand image prior to purchase, many of the small and medium-sized accommodations are primarily operated by micro-entrepreneurs who cannot afford to establish and maintain their own communication and distribution channels where consumers readily reach. Such alternative accommodations lack for standardization of their service or product and accordingly, assurance of service quality (García, Rama, \& Simonetti, 2016). The uncertainty about the service quality is generally considered a risk for customers, and for this reason, customers tend to avoid products with uncertainty(Littler \& Melanthiou, 2006). While the risk can be tolerably mitigated through dissemination of information through a website or other media(Stone \& Grønhaug, 1993), development and maintenance for the alternative accommodation owners of their own websites or distribution channels can be considered demanding practically and financially(Dombay, Seer, Magyari-Sáska, \& Seer, 2010). OTAs substantially relieve such issues, since customer search and evaluation of alternative accommodation is readily available on their platforms such as Bookings.com, Tripadvisor, Agoda, Expedia, etc. They also actively engage customers by providing a systematic rating scale and a review space for customers to share their stay experience.

\subsection{Attributes Affecting Customer Evaluation}

Most OTAs provide a standardized framework for the reviewers to evaluate and share the experience easily. The evaluation criteria of accommodation are often based on the relationship between service quality, customer perception, and post-experience behavior of a hotel that has been studied for a long time. Researchers have suggested service quality measurement for lodging properties such as LODGQUAL(Getty \& Thomson, 1994), LODGSERV (Knutson, Stevens, Wullaert, Patton, \& Yokoyama, 1990), and HOLSERV(Mei, Dean, \& White, 1999), on the basis of the celebrated seminal work SERVQUAL dimensions by Parasuraman, Zeithaml and Berry(1988). Though the five dimensions including tangibility, reliability, responsiveness, assurance, and empathy are inclusive and generalizable to service products, they do not always fully capture some contingent virtue such as value co-creation(Gronroos \& Voima, 2013; Smaliukiene et al., 2015; Vargo \& Lusch, 2004) or interaction between customers(Murphy, 2001; Park \& Santos, 2017; Sørensen, 2003). Continuously, customer evaluation criteria for accommodation has been evolved reflecting the market trend and external situations(Brochado, Rita, \& Gameiro, 2015; Ho \& Lee, 2007; Parasuraman, Zeithaml, \& Malhotra, 2005; Wu \& Ko, 2013).

Typical accommodation attributes for customer evluation include physical property, people, process, and food and beverage (F\&B) related factors(Bell \& Morey, 1996; Callan, 1998; Kim, Kim, \& Huo, 2016; Lewis, 1984; Ramanathan, 2012). Since the typical attributes are elemental components of accommodation, they are mostly accordant 
to alternative accommodation types. However, some hygiene factors such as security, safety, and/or sanitation are noted as more cared about in alternative accommodation, given the lack of standardization compared to conventional accommodation types(Amblee, 2015; Gunasekaran \& Anandkumar, 2012; Zervas, Proserpio, \& Byers, 2017). On the other hand, factors such as food and beverage or amenities add deviation in the scope or connotation. In many alternative accommodations, food and beverage is not an essential element, and the definition of amenities in P2P accommodation is not parallel with that of hotels. Amenities provided hotels are expected to be basic and expendable goods limited to room-use while amenities of alternative accommodation are supposed to include ancillary facilities and options equipped so that customers could use them(Belarmino et al., 2017; Tussyadiah \& Zach, 2017).

\section{Methodology}

\subsection{Research Design}

The objective of the present study is to explore the uniqueness of small and medium-sized alternative accommodation where value can be created in holistic customer experience. In order to achieve the objective, we developed a research design to comprehensively synthesize findings from both theory and practice. Synthesis of qualitative work provide further insights rich and amplified, which quantitative data may bypass(Wood, 2005). Therefore this study comprehensively synthesizes the current practices of industry, extent literature, and opinions of experts in the context of alternative accommodation. For the preliminary investigation, an in-depth interview with an industry expert is performed to capture the practical issues of the circumstances. Then, the rating frameworks of OTAs are examined to systematically code the practice. Based on the findings, a systematic review of the literature on alterative accommodation is conducted to explore the extended value-creating attributes beyond the basic attributes. A systematic review is an aggregative approach allowing compiling of the best evidence(Weed, 2005; 2008). Afterward, opinions of academic professionals are collected. Expert panel opinion is a useful method for professional exploration, complementing the procedural limitations of the Delphi method and obtaining the individual insights of selected experts by taking advantage of the in-depth interview method(Assaf, Josiassen, Woo, Agbola, \& Tsionas, 2017; Froschauer \& Lueger, 2009). The qualitative opinions by experts on the topic are particularly advantageous in grasping prospect and insight of the phenomenon where quantitative data is insufficiently accumulated under a versatile environment. <Figure 2> schematically illustrates the research design of the present study and the processes of each stage.

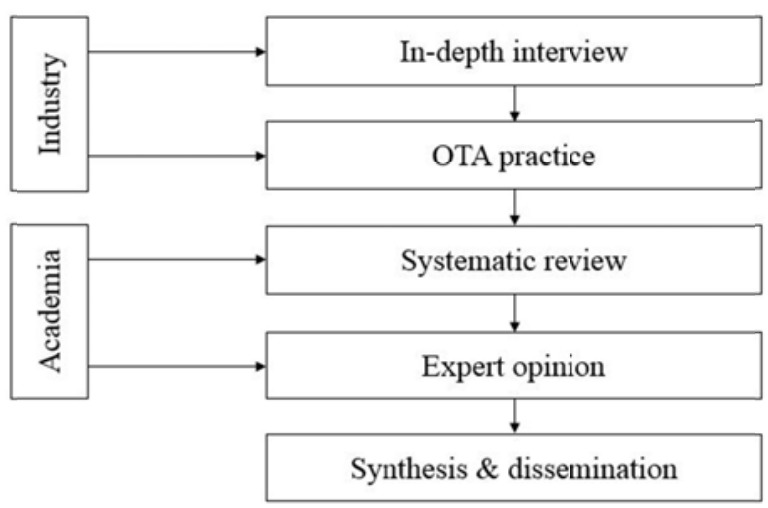

Figure 2. A synthesis approach: Illustration of analytical design and the processes of this study

\subsection{Procedure}

The preliminary in-depth interview with an industry expert was performed in April, 2016 in Seoul, Korea. The interviewee was an executive secretary of the relevant association, and the interview lasted around two hours. He first gave a talk on the actual circumstances on operating alternative accommodation, and answered the questions of the researchers derived from the literature and the interview. Based on the grasp of the practical background, customer review framework and the attributes on leading OTAs were examined in August, 2016. OTAs providing customer reviews on accommodation was searched based on the popularity and the diversity, and ten OTAs were sampled including "Booking.com", "Agoda.com", "Tripadvisor.com", and "Airbnb.com". In practice, leading OTAs were found to provide the customer rating framework of accommodation attributes consistent with the literature such as cleanliness, staff service, facilities condition, location, comfort, pricing, atmosphere, security, dining, and amenities.

For the next step to investigate further attributes and the value uniquely applicable to small and medium-sized alternative accommodation, a systematic review of the literature was performed between August and September in 2016, on the exclusion criteria predefined. The first criterion to narrow down the scope was to define the source of publication as leading journals in hospitality and tourism management. Seven journals were selected based on the informed judgment of the researchers: Annals of Tourism Research, Cornell Hospitality Quarterly, International Journal of Contemporary Hospitality Management, International Journal of Hospitality Management, Journal of 
Hospitality and Tourism Research, Journal of Travel Research, and Tourism Management. With the second criterion, we searched the journals through respective journal websites supplying electronic database using the keywords "guesthouse", "B\&B", "P2P accommodation", and "hostel". Under the third criterion, articles published before 2000 were excluded so as to configure the feature of electronic distribution. Out of more than a thousand articles retrieved from the initial screening, we first excluded them by the relevance of the titles. As under the fourth criterion that should contain evidence beyond the basic attributes, the filtered articles were further extracted to fit the scope and purpose of the study on hand, by the abstracts and the keywords. We yielded 14 articles meeting the criteria and the researcher semantically coded the attributes ranged outside of those found at the first step, and categorized the distinctive characteristics of alternative accommodation into the corresponding attributes of the comparative value. Attributes were classified into additional categories to the first categories, as social interaction(between host and guest, and between/among guests), flexibility, sustainability \& shared value, and technology acceptance. On the basis, we selected additional articles from the reference list of the papers and from Google Scholars with the attributes as the keywords, in order to compensate any valuable loss we might undergo.

By merging the findings from the prior stages, we generated an initial pool of the attributes of small and medium-sized alternative accommodation distributed via OTAs. The initial pool served as a minimal base for the expert panel opinion in the next research stage. Six professionals in the field of hospitality were solicited through purposive and snowball sampling and participated in the study. When selecting academic experts, their expertise on the topic was preferentially pondered. The member composition included four in Asia, one in the USA, and one from the Middle East. The panel members were instructed to provide the opinion on comparative attributes of alternative accommodation pertinent to customer evaluation and how to measure. The opinions were collected online, on the basis of the detailed initial pool attributes provided in the MS word format. The invited experts were asked to write as many opinions or comments as they wanted, without formality and constraint regarding the style. They were asked to provide their opinion within ten days, which allowed the panel members time to ruminate on the subject. The experts also provided further suggestions, comments, and/or further readings relevant to the topic and the study, all of which were valuable for the fulfillment of the current study. The researcher contacted the individual panels to clarify their opinions, and the iteration of the process ended when the researcher reached each line of panel opinions without confusion. Some predetermined compensation was provided to the panels for their contribution.

\section{Findings and Discussion}

\subsection{Basic Attributes}

$<$ Table $1>$ summarizes the basic accommodation-specific attributes, found in both the literature and the practice. The third level-expatiation-of the table contains the interpretation of each attribute in the context of alternative accommodation, and some of the expert opinions are directly quoted. The basic attributes are summarized and categorized into facility, location, food, price, staff, and F\&B. For the price attribute, economic benefits are often emphasized in alternative accommodation than in traditional hotels since young travelers and backpackers are substantial market segments for alternative accommodation. A lower price may increase the market share and accelerate the demand for alternative accommodation. However, value for money is a transcendental criterion of economic exchange, not restricted to alternative accommodation. Therefore, it is suggested that improvement in customer evaluation is achievable through under-researched dimensions such as social interaction, and adjustment of atmosphere or regulations not necessarily lowering price. It has also been noted that professional service is not a critical commodity of some alternative accommodations. While service and facilities are often regarded as core products for traditional hotels, simply sharing residential areas or renting the home is increasingly occupying the meaning of alternative accommodation where different expectation toward the hosts should be endowed.

\subsection{Extended Attributes}

On the foundation of the basics, unique attributes of alternative accommodation had been progressively supplemented at each stage. The attributes where comparative value can be created were summarized as being presented in <Table 2>. The first level-attribute- is the upper categories of the attributes as specified with the relevant items in the second level-relevant item. The third level includes the references, and the fourth levelexpatiation- discusses each attribute accentuated and interpreted from the perspective of alternative accommodation distributed via OTAs. Again, the quoted are the opinions of the experts. The extended attributes of comparative value subsume the attributes categorized into social interaction, flexibility, local touch, sustainability \& shared value, and technology acceptance. 
Table 1. Basic attributes of small and medium-sized alternative accommodation

\begin{tabular}{|l|l|l|}
\hline Attribute & \multicolumn{1}{|c|}{ Relevant Item } & \multicolumn{1}{c|}{ Expatiation } \\
\hline Facility & $\begin{array}{l}\text { Room } \\
\text { Beddings } \\
\text { Bathroom } \\
\text { Lighting } \\
\text { Furnishings } \\
\text { Path } \\
\text { Atmosphere/Ambience } \\
\text { Interior/Exterior } \\
\text { Amenities } \\
\text { Wi-Fi } \\
\text { Auxiliary facilities and services }\end{array}$ & $\begin{array}{l}\text { "Like traditional accommodation, alternative accommodation is not } \\
\text { exceptional in high dependence on the purpose of travel and travel } \\
\text { behavior of the guests. Facilities should be based on the target market." } \\
\text { "The facilities and spatial arrangement of alternative accommodations are } \\
\text { often different from the traditional accommodation types. } \\
\text { Hence, the attributes and the associated values assessed should be } \\
\text { universally applicable, and the valuation and the perceived importance } \\
\text { should be distinguished." }\end{array}$ \\
\hline \multirow{5}{*}{ Location } & $\begin{array}{l}\text { Property } \\
\text { Attractions } \\
\text { Surroundings } \\
\text { View/Scenery } \\
\text { Transportation }\end{array}$ & $\begin{array}{l}\text { While traditional accommodations seek locational advantage as } \\
\text { accessibility and the scenery, alternative accommodations can add value } \\
\text { by providing a local touch, authenticity, or exoticness, or by providing } \\
\text { special activities engaging the guests. }\end{array}$ \\
\hline Price & $\begin{array}{l}\text { Room rate } \\
\text { Facility usage } \\
\text { Service fee }\end{array}$ & $\begin{array}{l}\text { Price transparency has been accelerated by OTAs as a distribution } \\
\text { channel. Even if cost-saving is a rational appeal to consumers, the } \\
\text { demand for an alternative accommodation is not explained by their low } \\
\text { prices alone. }\end{array}$ \\
\hline Staff & $\begin{array}{l}\text { Hospitality } \\
\text { Process } \\
\text { Expertise }\end{array}$ & $\begin{array}{l}\text { For alternative accommodations, personal interaction goes beyond staff } \\
\text { service from the perspective of traditional accommodation. }\end{array}$ \\
\hline F\&B & $\begin{array}{l}\text { Food and Beverage (F\&B) options } \\
\text { Breakfast }\end{array}$ & $\begin{array}{l}\text { "There are a lot of alternative accommodation operations that do not have } \\
\text { F\& options, and thus the attributes spans the availability and the quality } \\
\text { inside and outside of the operations." }\end{array}$ \\
\hline
\end{tabular}

Table 2. Extended attributes of small and medium-sized alternative accommodation

\begin{tabular}{|l|l|l|l|}
\hline \multicolumn{1}{|c|}{ Attribute } & \multicolumn{1}{|c|}{ Relevant Item } & \multicolumn{1}{c|}{ Reference } & \multicolumn{1}{c|}{ Expatiation } \\
\hline $\begin{array}{l}\text { Social } \\
\text { Interaction }\end{array}$ & $\begin{array}{l}\text { Interaction with host } \\
\text { (online/offline) } \\
\text { Interaction with other guests } \\
\text { (online/offline) } \\
\text { Local touch }\end{array}$ & $\begin{array}{l}\text { Brochado et al. (2015); } \\
\text { Choo \& Petrick (2014); } \\
\text { Hassanli et al. (2016); } \\
\text { Hernández-Maestro \& } \\
\text { González-Benito (2013); } \\
\text { Murphy (2001); } \\
\text { Park \& Santos (2017); } \\
\text { Sørensen (2003) }\end{array}$ & $\begin{array}{l}\text { Direct and indirect, and online and on-site social } \\
\text { interactions not only between the supplier and consumer } \\
\text { but also between consumers who become the catalyst of } \\
\text { the subsequent attributes and affect the accommodation } \\
\text { experience. }\end{array}$ \\
\hline Flexibility & $\begin{array}{l}\text { Policy } \\
\text { Process }\end{array}$ & $\begin{array}{l}\text { Hassanli et al. (2016); } \\
\text { Park \& Santos (2017) }\end{array}$ & $\begin{array}{l}\text { "The handling of the operational process (e.g., check- } \\
\text { in/out, cancellation, etc.) is expected to be more flexible } \\
\text { in an alternative accommodation." }\end{array}$ \\
\hline $\begin{array}{l}\text { Sustainability \& } \\
\text { Shared value }\end{array}$ & $\begin{array}{l}\text { Ethical standards } \\
\text { Financial longevity } \\
\text { Operational consistency } \\
\text { Eco-friendly } \\
\text { (The consequent e-WOM) }\end{array}$ & $\begin{array}{l}\text { Jones et al. (2016); } \\
\text { Tussyadiah (2016) } \\
\text { alternative accommodations often suffer from financial } \\
\text { problems." } \\
\text { "Since many alternative accommodation operations are } \\
\text { unauthorized or unlicensed, the scope of sustainability } \\
\text { for alternative accommodations span metaphysically } \\
\text { from legality to ethicality." }\end{array}$ \\
\hline $\begin{array}{l}\text { Technology } \\
\text { Acceptance }\end{array}$ & $\begin{array}{l}\text { Transaction } \\
\text { Partnership } \\
\text { Operation } \\
\text { System } \\
\text { Infrastructure }\end{array}$ & $\begin{array}{l}\text { Buhalis \& Law (2008); } \\
\text { Inversini \& Masiero, } \\
(2014) ; \\
\text { Kim, Lee, \& Law (2008) }\end{array}$ & $\begin{array}{l}\text { Though aggressive technology innovation is not easily } \\
\text { realizable to micro-sized operations of alternative } \\
\text { accommodation, technology acceptance is vital for them } \\
\text { to keep up with the times. }\end{array}$ \\
\hline
\end{tabular}


Although it is not always or not necessarily the case, social interaction is a unique feature of alternative accommodation. The social subjects are further divided into the Host to Guest $(\mathrm{H} 2 \mathrm{G})$ interaction and the Guest to Guest(G2G) interaction. While the owners or the CEOs of traditional accommodation are rarely expected to have personal and direct communication with their guests, small and medium-sized alternative accommodation types such as P2P accommodations or commercial homes appreciably involve occasions of such direct contact, which is $H 2 G$ interaction. Likewise, the G2G was only sought in some specific types of accommodations such as hostels and guesthouses with a communal area. For the accommodation sectors where the rooms are spatially exclusive and independent, G2G was not readily available or expected. However, an online platform enabled both types of communication, outside of temporal and spatial boundaries. Higher reliance on OTAs as a distribution channel and uncertainty of the quality further facilitate customers to seek and share their experience and the valence online, which can either be temporally dynamic(Oh, 2017). Such willingness to socially interact reach to the third attribute, local touch, which can fulfill novelty- and diversityseeking needs as well as experiential needs of travelers. They want to be reconciled with the neighbors and the destination and thus aspire home to make them feel resident, not a visitor. Consequently, room for flexibility in alternative accommodation is magnified through the interactions, particularly $\mathrm{H} 2 \mathrm{G}$ interaction. Flexibility, the second attribute, is not synonymous with 'whatever the guest wants', but the availability of prior consultation on a contingent situation of the guest via the personalized communication channel. Hence, subjective and emotional characteristics of alternative accommodation are distinct.

The third attribute is sustainability and shared value. Traditionally, sustainability in traditional lodging sectors has primarily focused on environmental friendliness and green initiatives(e.g., Berezan, Raab, Yoo, \& Love, 2013; Kasim, Gursoy, Okumus, \& Wong, 2014). However, the sustainable ecosystem is gradually urged to be expanded to economic, social as well as environmental domains(Jones, Hillier, \& Comfort, 2016), considering the multifaceted impact of a practice. Creating shared value refers to the creation of economic and societal benefits relative to cost by a firm with the community(Porter \& Kramer, 2011). By considering and developing the contingent relationships both internal and external, the firm can expect better performance and the returns, providing benefits to the employees, the customers, the competitors, and the community thus creating shared value(Lee \& Kim, 2015; Porter, Hills, Pfitzer, Patscheke, \& Hawkins, 2011). Legal compliance and ethical responsibility are the issues which cannot be overlooked for the business longevity since small and micro-sized accommodation is comparatively easy to evade the law concerning regulation or registration. The absence of systematic management sometimes forces the customers into unsecured or unjustified situations. In this regard, practices to build credibility with the customers are associated with perceived risk concerning safety, security, finance, and social responsibility and legality. Such internal affairs below the surface seldom used to be known outside, but can be spread out and recorded on the third-party channel, which is difficult for the accommodation enterprises to control, relatively easily by e-WOM. Alternative accommodations can enhance their competitiveness through the policies and executions while simultaneously contributing to the betterment of their communities socially and economically.

The last but not the least important attribute is technology acceptance. Even if alternative accommodation business is not an information technology-driven business, technology acceptance should be a minimal degree of sustainable competence in the contemporary era. The technology-use of consumers are increasingly mobilized and universalized, and entrepreneurs and marketers who keep up with the changing environment have higher opportunity to take advantage by actively engaging social interaction and flexibility(Buhalis \& Law, 2008; Inversini \& Masiero, 2014; Kim, Lee, \& Law, 2008). Small and medium enterprises not sufficiently adopting technological innovation in the operational management or equipping devices can embrace technological covers by making a partnership or strategic alliance with relevant sources. As OTAs have brought synergetic interaction with alternative accommodation, use of OTAs as distribution and promotion channel is a good example.

\section{Conclusion}

OTA is a critical distribution channel, particularly for alternative accommodation. The alternative accommodation sector has grown dramatically in recent decades, and the overwhelming success is not fully explained without the development of information technology and the utilization of OTAs as a distribution channel. For better understanding the phenomenon from an interactive perspective, the comparative values of small and medium-sized alternative accommodation have been explored based on the evidence of the literature, OTA practices, and expert opinions, by comprehensively synthesizing the available sources. The basic attributes of accommodation actively acknowledged by both theory and practice include facility, location, price, staff, and $F \& B$, and this study interpreted the messages behind in the setting of alternative accommodation. A 
systematic review and expert opinions have suggested four additional attributes of comparative value, represented by social interaction, flexibility, sustainability \& shared value, and technology adoption. Given the temporal and spatial dynamics in the consumer experience ranging from searching and webrooming to staying and post-staying online behavior, we believe that the comprehensive and synthetic perspective provides a useful view of alternative accommodation distributed by OTAs to both academic and industry audiences.

From a theoretical aspect, the conceptual foundation for collectively comprehending the comparative value of small and medium-sized alternative accommodation for the customers is in an embryonic phase of theoretical development. The present study extends the conceptual background and the attributes to create comparative value by integrating alternative accommodation and the online intermediary represented by OTAs. The differentiation and uniqueness of small and medium-sized alternative accommodation from the traditional have been excavated in consideration of the holistic process of customer experience from on-line to off-line, and from pre-stay to post-stay. The findings would be a useful base for the comparative studies distinguishing traditional and alternative accommodation, and the studies of alternative accommodation whose influence is leveraged in the contemporary era.

The methodological framework for the synthesis is another significance of our study. Our synthetic approach has engaged the primary sources as industrial and academic experts and the secondary sources as industrial cases and the literature. The combined nature of the synthetic approach in this study will lead to not only the conceptual innovation and synergistic interaction for the topic and the methods but exploration of a phenomenon in more objective and balanced perspectives. The approach can be particularly useful where various sources of data are available while one source is insufficient.

From a practical point of view, effectively serving the potential areas where values are created can help gain a competitive advantage for the entrepreneurs and marketers of alternative accommodation. Fewer studies have been directed to examining how micro-business owners and managers should manage their operations, in light of satisfying the customers in the attributes where they place importance. As such, it should be reiterated that the findings of this study are subtle but consequential to the industry, specifically to the third-party distribution platforms and merchant websites. For example, the current customer rating criteria suggested by OTAs can be improved forthwith for alternative accommodation based on the findings of the study. The competition with traditional and alternative accommodation types in the indistinguishable online evaluation frameworks can be disadvantageous for both parties given the asymmetries between the two, considering the difference in market segments and the value proposition.

Notwithstanding the originality, the present research is not free from limitations. First, the findings of this study may not be generalized to all of the market or every situation. Although the interview and expert opinions were consistent with the evidenced found in the literature, the perspective and interpretation may not be consistent across cultures and market environments. Some important findings might be lost in the systematic review, and this might happen to the expert opinions as well. Second, the five basic and four extended attributes explored in this study are to be the sources of comparative value, but the enumerative weights or path of the attributes to latent variables have not been addressed. Empirically examining the relationship and the impact of the respective attributes would be a significant extension of the current study.

\section{References}

Amblee, N. (2015). The impact of cleanliness on customer perceptions of security in hostels: A WOM-based approach. International Journal of Hospitality Management, 49, 37-39.

Assaf, A. G., Josiassen, A., Woo, L., Agbola, F. W., \& Tsionas, M. (2017). Destination characteristics that drive hotel performance: A state-of-the-art global analysis. Tourism Management, 60, 270-279.

Bastakis, C., Buhalis, D., \& Butler, R. (2004). The perception of small and medium sized tourism accommodation providers on the impacts of the tour operators' power in Eastern Mediterranean. Tourism Management, 25(2), 151-170.

Belarmino, A., Whalen, E., Koh, Y., \& Bowen, J. T. (2017). Comparing guests' key attributes of peer-to-peer accommodations and hotels: Mixed-methods approach. Current Issues in Tourism, 1-7. Retrieved March 20, 2018 from https://www.tandfonline.com/ doi/abs/10.1080/13683500.2017.1293623

Bell, R. A., \& Morey, R. C. (1996). Purchase situation modeling: The case of hotel selection criteria for corporate travel departments. Journal of Travel Research, 35(1), 57-63.

Berezan, O., Raab, C., Yoo, M., \& Love, C. (2013). Sustainable hotel practices and nationality: The impact on guest satisfaction and guest intention to return. International Journal of Hospitality Management, 34, 227-233.

Blum, L. S. (2014). The popularity of guesthouses. The Wall Street Journal. Retrieved March 20, 2018 from 
https://www.wsj.com/articles/the-popularity-ofguesthouses-1408638276

Brochado, A., \& Rita, P. (2016). Exploring heterogeneity among backpackers in hostels. Current Issues in Tourism. Retrieved March 20, 2018 from https://www.tandfonline.com/doi/abs/10.1080/136835 00.2016 .1252728

Brochado, A., Rita, P., \& Gameiro, C. (2015). Exploring backpackers' perceptions of the hostel service quality. International Journal of Contemporary Hospitality Management, 27(8), 1839-1855.

Buhalis, D., \& Law, R. (2008). Progress in information technology and tourism management: 20 years on and 10 years after the Internet - The state of eTourism research. Tourism Management, 29(4), 609-623.

Callan, R. J. (1998). Attributional analysis of customers' hotel selection criteria by UK grading scheme categories. Journal of Travel Research, 36(3), 20-34.

Choo, H., \& Petrick, J. F. (2014). Social interactions and intentions to revisit for agritourism service encounters. Tourism Management, 40, 372-381.

Dombay, Ş., Seer, L., Magyari-Sáska, Z., \& Seer, M. (2010). Marketing activity of guesthouses and other hospitality units from Harghita, Mures and Covasna countries. International Journal of Applied Mathematics and Informatics, 4(4), 103-110.

Froschauer, U., \& Lueger, M. (2009). Expert interviews in interpretive organizational research. In Bogner, A., Littig, B., \& Menz, W. (Eds.). Interviewing experts (pp. 217-234). London, UK: Palgrave Macmillan.

García, J. Á., Del Río, M. C., \& Simonetti, B. (2016). Implementation of a quality management system in rural accommodations: Perceived benefits. International Journal of Business and Society, 17(1), 63-80.

Gardiner, S., \& Scott, N. (2014). Successful tourism clusters: Passion in paradise. Annals of Tourism Research, 46, 171-173.

Gazzoli, G., Kim, W. G., \& Palakurthi, R. (2008). Online distribution strategies and competition: Are the global hotel companies getting it right?. International Journal of Contemporary Hospitality Management, 20(4), 375-387.

Getty, J. M., \& Thompson, K. N. (1994). A procedure for scaling perceptions of lodging quality. Hospitality Research Journal, 18(2), 75-96.

Grönroos, C., \& Voima, P. (2013). Critical service logic: making sense of value creation and co-creation. Journal of the Academy of Marketing Science, 41(2), 133-150.
Gunasekaran, N., \& Anandkumar, V. (2012). Factors of influence in choosing alternative accommodation: A study with reference to Pondicherry, a coastal heritage town. Procedia-Social and Behavioral Sciences, 62, 1127-1132.

Guttentag, D. A., \& Smith, S. L. (2017). Assessing Airbnb as a disruptive innovation relative to hotels: Substitution and comparative performance expectations. International Journal of Hospitality Management, 64, $1-10$.

Hassanli, N., Gross, M. J., \& Brown, G. (2016). The emergence of home-based accommodations in Iran: A study of self-organization. Tourism Management, 54, 284-295.

Hernández-Maestro, R. M., \& González-Benito, Ó. (2014). Rural lodging establishments as drivers of rural development. Journal of Travel Research, 53(1), 8395.

Ho, C. I., \& Lee, Y. L. (2007). The development of an etravel service quality scale. Tourism Management, 28(6), 1434-1449.

Inversini, A., \& Masiero, L. (2014). Selling rooms online: The use of social media and online travel agents. International Journal of Contemporary Hospitality Management, 26(2), 272-292.

Jones, P., Hillier, D., \& Comfort, D. (2016). Sustainability in the hospitality industry: Some personal reflections on corporate challenges and research agendas. International Journal of Contemporary Hospitality Management, 28(1), 36-67.

Kang, J. M. (2018). Showrooming, webrooming, and usergenerated content creation in the omnichannel era. Journal of Internet Commerce, 1-25. Retrieved March 20, 2018 from https://www.tandfonline.com/ doi/abs/10.1080/15332861.2018.1433907?src=recsy s\&journalCode=wico20

Kasim, A., Gursoy, D., Okumus, F., \& Wong, A. (2014). The importance of water management in hotels: A framework for sustainability through innovation. Journal of Sustainable Tourism, 22(7), 1090-1107.

Kim, B., Kim, S., \& Heo, C. Y. (2016). Analysis of satisfiers and dissatisfiers in online hotel reviews on social media. International Journal of Contemporary Hospitality Management, 28(9), 1915-1936.

Kim, T. G., Lee, J. H., \& Law, R. (2008). An empirical examination of the acceptance behaviour of hotel front office systems: An extended technology acceptance model. Tourism Management, 29(3), 500-513.

Knutson, B., Stevens, P., Wullaert, C., Patton, M., \& Yokoyama, F. (1990). LODGSERV: A service quality 
index for the lodging industry. Journal of Hospitality \& Tourism Research, 14(2), 277-284.

Law, R., Leung, R., Lo, A., Leung, D., \& Fong, L. H. N. (2015). Distribution channel in hospitality and tourism: Revisiting disintermediation from the perspectives of hotels and travel agencies. International Journal of Contemporary Hospitality Management, 27(3), 431452.

Lee, Y., \& Kim, Y. (2015). A study on CSV of social economy and consumer perspective. Journal of Distribution Science, 13(12), 53-63.

Lewis, R. C. (1984). Isolating differences in hotel attributes. Cornell Hotel and Restaurant Administration Quarterly, 25(3), 64-77.

Li, Y., Hu, C., Huang, C., \& Duan, L. (2017). The concept of smart tourism in the context of tourism information services. Tourism Management, 58, 293-300.

Littler, D., \& Melanthiou, D. (2006). Consumer perceptions of risk and uncertainty and the implications for behaviour towards innovative retail services: The case of internet banking. Journal of Retailing and Consumer Services, 13(6), 431-443.

Lynch, P. A. (2005). The commercial home enterprise and host: A United Kingdom perspective. International Journal of Hospitality Management, 24(4), 533-553.

Mei, A. W. O., Dean, A. M., \& White, C. J. (1999). Analyzing service quality in the hospitality industry. Managing Service Quality: An International Journal, 9(2), 136143.

Morosan, C., \& Jeong, M. (2008). Users' perceptions of two types of hotel reservation web sites. International Journal of Hospitality Management, 27(2), 284-292.

Morrison, A. M., Pearce, P. L., Moscardo, G., Nadkarni, N., \& O'Leary, J. T. (1996). Specialist accommodation: Definition, markets served, and roles in tourism development. Journal of Travel Research, 35(1), 1826.

Murphy, L. (2001). Exploring social interactions of backpackers. Annals of Tourism Research, 28(1), 50-67.

Niner, P. (2004). Accommodating nomadism? An examination of accommodation options for Gypsies and Travellers in England. Housing Studies, 19(2), 141-159.

Oh, Y. (2017). The effect of review behavior on the reviewer's valence in online retailing. Journal of Distribution Science, 15(10), 41-50.

Parasuraman, A., Zeithaml, V. A., \& Malhotra, A. (2005). ES-QUAL a multiple-item scale for assessing electronic service quality. Journal of Service Research, 7(3), 213-233.
Parasuraman, A., Zeithaml, V., \& Berry, L. (1988). Servqual. Journal of Retailing, 64(1), 12-40.

Park, S., \& Santos, C. A. (2017). Exploring the Tourist Experience: A Sequential Approach. Journal of Travel Research, 56(1), 16-27.

Pearce, P. L., \& Moscardo, G. M. (1992). The boutique/ specialist accommodation sector: Perceived government needs and policy initiatives. Queensland Small Business Research Journal, 38, 34-41.

Porter, M., \& Kramer, M. R. (2011). Creating shared value. Harvard Business Review, 89(1/2), 62-77.

Porter, M. E., Hills, G., Pfitzer, M., Patscheke, S., \& Hawkins, E. (2011). Measuring shared value: How to unlock value by linking social and business results. Retrieved March 20, 2018, from www.fsg.org/Portals/0/Uploads/Documents/PDF/Mea suring_Shared_Value.pdf

Ramanathan, R. (2012). An exploratory study of marketing, physical and people related performance criteria in hotels. International Journal of Contemporary Hospitality Management, 24(1), 44-61.

Schwaniger, M. (1989). Strategic Management in Tourism. In S. F. Witt, \& L. Moutinho (Eds.). Tourism Marketing and Management Handbook (pp.57-67). New York: Prentice Hall.

Smaliukiene, R., Chi-Shiun, L., \& Sizovaite, I. (2015). Consumer value co-creation in online business: The case of global travel services. Journal of Business Economics and Management, 16(2), 325-339.

Sørensen, A. (2003). Backpacker Ethnography. Annals of Tourism Research, 30(4), 847-867.

Sthapit, A, Jo, G., \& Hwang, Y. (2016). Construal levels and online shopping: Antecedents of visits to and purchases from online retailers' websites. International Journal of Industrial Distribution \& Business, 7(3), 19-25.

Stone, R. N., \& Grønhaug, K. (1993). Perceived risk: Further considerations for the marketing discipline. European Journal of Marketing, 27(3), 39-50.

Thakran, K., \& Verma, R. (2013). The emergence of hybrid online distribution channels in travel, tourism and hospitality. Cornell Hospitality Quarterly, 54(3), 240247.

Tussyadiah, I. P., \& Zach, F. (2017). Identifying salient attributes of peer-to-peer accommodation experience. Journal of Travel \& Tourism Marketing, 34(5), 636652.

Tussyadiah, I. P. (2016). Factors of satisfaction and intention to use peer-to-peer accommodation. International Journal of Hospitality Management, 55, 70-80. 
Vargo, S. L., \& Lusch, R. F. (2004). Evolving to a new dominant logic for marketing. Journal of Marketing, 68(1), 1-17.

Verhoef, P. C., Kannan, P. K., \& Inman, J. J. (2015). From multi-channel retailing to omni-channel retailing: Introduction to the special issue on multi-channel retailing. Journal of Retailing, 91(2), 174-181.

Weed, M. (2005). Meta interpretation: A method for the interpretive synthesis of qualitative research. Forum: Qualitative Social Research, 6(1), 1-21.

Weed, M. (2008). A potential method for the interpretive synthesis of qualitative research: issues in the development of 'meta-interpretation'. International Journal of Social Research Methodology, 11(1), 1328.

Wu, H. C., \& Ko, Y. J. (2013). Assessment of service quality in the hotel industry. Journal of Quality Assurance in Hospitality \& Tourism, 14(3), 218-244.

Zervas, G., Proserpio, D., \& Byers, J. W. (2017). The rise of the sharing economy: Estimating the impact of Airbnb on the hotel industry. Journal of Marketing Research, 54(5), 687-705. 